\title{
Heterogeneous cerebral glucose metabolism in normal pressure hydrocephalus
}

Enrico Tedeschi, Steen G Hasselbalch, Gunhild Waldemar, Marianne Juhler, Peter Høgh, Søren Holm, Lars Garde, Lisbet Lumholdt Knudsen, Leif Klinken, Flemming Gjerris, Olaf B Paulson

\begin{abstract}
The regional cerebral metabolic rate for glucose $\left(\mathbf{r C M R} \mathbf{R}_{\text {glu }}\right)$ has never been investigated in large consecutive groups of patients with normal pressure hydrocephalus (NPH), a potentially treatable form of dementia with an unpredictable outcome after shunt surgery. Using PET and ${ }^{18} \mathbf{F}$-2-fluorodeoxyglucose, $\mathbf{r C M R}_{\text {glu }}$ was studied in 18 patients who fulfilled hydrodynamic criteria for NPH and in whom a biopsy of the frontal cortex was obtained. When compared with an age matched group of 11 healthy subjects, the patients with NPH showed a significant $\mathbf{r C M R}_{\text {glu }}$ reduction in all cortical and subcortical regions of interest. Individual metabolic patterns, however, disclosed a large topographical heterogeneity. Furthermore, histopathological examination identified Alzheimer's disease or cerebrovascular disease in six cases, and no parenchymal disease or non-specific degenerative processes in the remaining 12. After separating the patients according to the histological diagnosis, the $\mathbf{r C M R}_{\text {glu }}$ patterns were still heterogeneous, the abnormalities ranging from focal to diffuse in both subgroups. After shunt operation, 11 patients did not improve or worsened clinically. Six patients improved; of those, two had Alzheimer changes and two cerebrovascular changes in their biopsy. The metabolic pattern of these six patients did not differ from the rest of the NPH group.

The results indicate that the NPH syndrome may be non-specifically associated with different degenerative disorders. The metabolic heterogeneity, together with the heterogeneous histopathological findings, indicate the necessity of reevaluating the pathogenesis of the NPH syndrome, and may account for the high variability in the success rate of shunt surgery series.
\end{abstract}

(F Neurol Neurosurg Psychiatry 1995;59:608-615)

Keywords: cerebral glucose metabolism; normal pressure hydrocephalus

The use of functional brain imaging for diagnosing and studying the pathophysiology of dementia is increasing. The normal pressure hydrocephalus (NPH) syndrome is a potentially treatable form of dementia, clinically characterised by gait apraxia, urinary inconti- nence, and progressive dementia. It is also known as Hakim's triad or NPH syndrome. ${ }^{12}$ Although NPH symptoms are accepted as a clinical entity and the ventricular enlargement can be quantified on CT or MRI, it is sometimes not easy to differentiate in vivo atypical or endstage cases from other types of dementia, particularly from dementia of the Alzheimer type (DAT), probably due to a large overlap of clinical and radiological findings. Cerebrospinal fluid shunt surgery or CSF evacuation through repeated lumbar punctures can dramatically reverse the NPH syndrome, ${ }^{13}$ but the success rate is highly variable. Even when applying strict hydrodynamic criteria in selecting patients for surgery, there is still a significant fraction of cases who do not benefit from CSF drainage. ${ }^{24-6}$

Regional cerebral glucose $\left(\mathrm{rCMR}_{\mathrm{glu}}\right)$ and oxygen $\left(\mathrm{rCMRO}_{2}\right)$ metabolism have been extensively measured with PET and ${ }^{18} \mathrm{~F}$-2-fluorodeoxyglucose (FDG) in DAT..$^{7-10}$ On the other hand, no PET studies of cerebral blood flow, $\mathrm{rCMRO}_{2}$, or $\mathrm{rCMR}_{\mathrm{glu}}$ have included an adequate number of consecutive patients to describe a specific pattern of metabolic derangement in NPH. ${ }^{11-14}$ The cerebral blood flow findings from single photon emission computed tomography (SPECT) studies in $\mathrm{NPH}$ are very heterogeneous in the extent and location of the cortical deficits, ${ }^{15-18}$ and imaging of subcortical regions has recently offered interesting perspectives. ${ }^{19} 20$

Considering the heterogeneity in the perfusion findings and the variability in the success rate of shunt surgery, the aim of the present study was to test the hypothesis that different PET-FDG patterns were present in patients with NPH, due to the possible coexistence of different underlying degenerative processes. We therefore measured $\mathrm{rCMR}_{\text {glu }}$ with PETFDG in 18 patients fulfilling hydrodynamic criteria for NPH in whom a small brain biopsy was obtained from the right frontal region. We also aimed to match PET-FDG patterns with biopsy results, to achieve a thorough morphofunctional characterisation in patients with NPH. The metabolic alterations were evaluated in relation to the histological findings, the severity of the clinical symptoms, and the response to shunting.

\section{Materials and methods}

\section{PATIENTS}

In a two year period, all patients younger than 80 years who were referred to the department of neurosurgery at Rigshospitalet Copenhagen 
with clinical and radiological findings suggestive of NPH were asked to enter the study. A final diagnosis of NPH was based on the following previously validated ${ }^{25}$ criteria: (a) personal history and clinical evidence of two or more symptoms of the NPH syndrome at the neurological evaluation; (b) significant ventricular enlargement on CT (Evans' ratio $\geqslant 0 \cdot 30),{ }^{521}$ and $(c)$ hydrodynamic criteria (see CSF perfusion study and biopsy).

This report includes all the patients with a final diagnosis of NPH, in whom a brain MRI study, PET-FDG, and a frontal biopsy were obtained. A total of 18 consecutive patients (10 men, eight women, mean age 63.4 , range 46-76 years) was thus selected, comprising only patients with socalled "idiopathic" NPH, as no history of significant head trauma, meningitis, subarachnoid haemorrhage, or other causes known to be associated with the development of NPH were reported.

\section{STUDY PROGRAMME}

On admission of the patients a trained neurologist performed a clinical and neurological evaluation paying special attention to gait, sphincter function, and cognitive status. Gait was rated on a point scale $(1=$ normal, 2 = abnormal but possible without support, 3 = need of cane, $4=$ need of support of another person, $5=$ bedridden); likewise, urinary incontinence was rated as $1=$ none, $2=$ rare, $3=$ occasional, $4=$ constant, 5 = catheter. The presence of dementia was evaluated according to DMS III-R criteria, ${ }^{22}$ its severity was assessed with the mini mental state examination (MMSE ${ }^{23}$ ), and the global deterioration scale $\left(\mathrm{GDS}^{24}\right)$. Scores for MMSE were also obtained in the control subjects.

In all patients and control subjects a standard laboratory test battery was performed. Both groups underwent cranial MRI and PET-FDG and the patients with NPH also had a CSF perfusion study and a brain biopsy. Three to nine months after shunt operation, the clinical response to the operation was assessed. A trained neurologist scored the patients as described, and changes in the clinical condition were semiquantitatively evaluated by calculating the change in the sum of scores. The clinical status was graded as worsened, unchanged, slightly improved, or considerably improved.

All subjects and patients (with their relatives) gave informed consent to participate in the study, which was approved by the local ethics committee (protocol No V. 100.1500/90).

\section{CONTROL SUBJECTS}

Eleven healthy subjects (six men, five women, mean age 62 (range 53-75 years), recruited by advertisement, volunteered for the study. The subjects had no family history of dementia and no personal history of any psychiatric or neurological disease, severe head trauma, any metabolic or endocrine disturbances, cancer, severe hypertension, heart disease, or alcohol or drug misuse. Neurological and neuropsychological examination disclosed no abnormalities (MMSE scores > 27). The brain MRI was described as normal by a trained radiologist.

MRI

Using conventional spin echo sequences $(\mathrm{TR}=2000 \mathrm{~ms}, \mathrm{TE}=30-90 \mathrm{~ms})$ on a 0.3 Tesla MR tomograph (FONAR, USA), the proton density weighted images of nine transverse brain slices were obtained. Slice thickness was $10 \mathrm{~mm}$, with an interslice distance of $12 \mathrm{~mm}$. In one patient the MRI was technically inadequate because of movement artefacts; instead, a cranial CT was performed.

PET-FDG

The subject was placed supine, in quiet, dim surroundings, with eyes closed and ears unplugged from 30 minutes before to 40 minutes after the intravenous injection of 180-250 MBq FDG. Starting simultaneously with FDG injection, $1.5 \mathrm{ml}$ blood samples were drawn from the radial artery with increasing time intervals, then placed on ice and centrifuged. Plasma activity was counted in a gamma counter (COBRA 50003, Packard Instruments, Downers Grove, Illinois).

Some 40 to 50 minutes after injection, the subject was moved to the couch of the Therascan 3128 PET scanner (Atomic energy Ltd, Canada) and three scans were performed, in wobble mode, for a total scan time of 45 minutes. To avoid head movements during the scan, the head was fixed by an individually moulded cushion made of a two component foam. Nine consecutive slices, $12 \mathrm{~mm}$ thick, with an image plane resolution of $10-12 \mathrm{~mm}$ were thus obtained. Correction for dead time, randoms, scatter, and attenuation was performed as previously described. ${ }^{25}$ The corrected count rate was $0 \cdot 6-1 \cdot 4^{6} \times 10$ counts per slice. Calibration of the PET camera and cross calibration with the gamma counter were performed at the end of the day.

Regional $\mathrm{CMR}_{\mathrm{glu}}$ was measured by the autoradiographic approach first described by Sokoloff $e t a l,{ }^{26}$ and later modified by Brooks. ${ }^{27}$ The following fixed values for the rate constants were used: $k_{1}=0 \cdot 105, k_{2}=0 \cdot 126, k_{3}=$ 0.075 , and $k_{4}=0.0068$. The lumped constant was fixed at $0 \cdot 56$. Plasma glucose concentrations during the study were obtained by averaging several measurements performed with a Beckman glucose analyser (Beckman Instruments Inc, USA).

\section{POSITIONING}

The canthomeatal plane was used as a reference for MRI and PET-FDG, and the midplanes of the nine slices were placed at the same levels above the canthomeatal plane for both studies. The transaxial MR slices were tilted according to the canthomeatal plane, identified on the sagittal MR T1 weighted ( $T R=500 \mathrm{~ms}, \mathrm{TE}=25 \mathrm{~ms})$ image which displayed a small vaseline filled tube fixed to the skin. The same positioning was obtained for the PET-FDG study using a laser beam parallel to the canthomeatal line. As slice thickness was roughly the same (MRI: $10 \mathrm{~mm}$, 
PET: $12 \mathrm{~mm}$ ), the volume of the brain covered by these scans was easily comparable.

\section{DATA ANALYSIS}

Although automatic $\mathrm{CO}$ registration of $\mathrm{MRI}$ and PET-FDG was not achievable at the time of the study, the use of a common positioning technique and an atlas derived region of interest definition, made it possible to easily identify brain structures on MRI and corresponding functional areas on PET-FDG. With reference to an anatomic atlas, ${ }^{28}$ nine brain levels, parallel to the canthomeatal plane separated by $10 \mathrm{~mm}$ were selected. In each of these levels, a template of symmetric cortical and subcortical regions of interest was defined, as previously described in detail. ${ }^{29}$ For each level, the region of interest template was drawn on the MRI slice and then applied to the PET image, using a VAX station. It was only allowed to redraw or adjust the precise location of central grey matter structures, white matter regions, and the outer boundaries of the brain, as minute positioning errors between MRI and PET had the greatest influence on these areas. The regions of interest were incorporated into larger regions of meaningful anatomical localisation, which could comprise several slices. ${ }^{29}$ The weighted mean metabolism value of the larger regions of interest was calculated from the mean pixel value and the area of the region for each slice in which the region of interest appeared. Furthermore, asymmetry ratios within individual subjects were calculated between leftright and anterior-posterior corresponding regions of interest. In particular, for each region of interest, a side to side asymmetry index (SAI) in respect to the contralateral region, was calculated:

$$
\operatorname{SAI}_{1}(\%)=100 \times\left(\left[\mathrm{M}_{\mathrm{i}(\mathrm{R})}-\mathrm{M}_{\mathrm{i}(\mathrm{L})}\right] / \mathrm{M}_{\mathrm{i}(\max )}\right)
$$

where $M_{R}$ and $M_{L}$ are the weighted mean metabolic values in the right and the left counterparts of the two regions of interest respectively, and $M_{\max }$ is the highest of these two values. Frontotemporal and frontoparietal ratios (anterior/posterior ratios) were calculated, to detect possible internal asymmetries, also along the anterior-posterior axis of the brain.

For the individual characterisation of the metabolic patterns in patients and controls, the absolute $\mathrm{CMR}_{\mathrm{glu}}$ and the within subject side to side asymmetry indices and the anterior-posterior ratios were calculated dividing the cerebal cortex into three symmetric main regions: ( $a$ ) frontal, left, and right, (b) temporal, left, and right, and (c) parietal, left and right. A normality range (mean (2 SD)) for both absolute $\mathrm{CMR}_{\mathrm{glu}}$ values and internal asymmetry ratios was defined from the control material and regions outside the range were considered abnormal. A "metabolic impairment score", expressing both the absolute reduction in cortical $\mathrm{rCMR}_{\mathrm{glu}}$ and the presence of within subject cortical asymmetries was then assigned to each individual PET-FDG pattern. In particular, 1 point was given for any region resulting in abnormal absolute $\mathrm{rCMR}_{\mathrm{glu}}$ or in internal asymmetry and 1.5 points for any region with both absolute $\mathrm{rCMR}_{\mathrm{glu}}$ reduction and increased internal asymmetry. Metabolic impairment score values (range 0-8) thus enabled us to pinpoint abnormal regions in every patient with NPH. Also, ratios between $\mathrm{rCMR}_{\mathrm{glu}}$ values in the association cortex (middle frontal gyrus and angular-supramarginal parietal gyrus) $v$ primary cortex (precentral and postcentral gyri) and $v$ subcortical grey matter (basal ganglia regions of interest) were obtained in every patient and control subject and correlated with the histological findings.

\section{CSF PERFUSION STUDY AND BIOPSY}

The patients underwent a lumboventricular perfusion test with measurement of the resistance to CSF outflow ${ }^{2}$ and a 24 hour monitoring of intracranial pressure. Increased resistance to CSF outflow ( $>10 \mathrm{~mm} \mathrm{Hg} / \mathrm{ml} /$ $\mathrm{min}$ ) with a normal or slightly raised intracranial pressure $(<15 \mathrm{~mm} \mathrm{Hg}$ ) were required for the final diagnosis of NPH. One to four weeks later, during the placement of a ventriculoperitoneal shunt through the same burr hole, a small $\left(<1 \mathrm{~cm}^{3}\right)$ biopsy was taken from the right superior frontal cortex and underlying white matter, avoiding the tissue affected by the earlier intracranial pressure measurement and without electrocoagulating the tissue before its excision.

Five $\mu \mathrm{m}$ thick slices of the formalin fixed, paraffin embedded biopsy specimens were stained with standard dyes (haematoxylineosin, perodic acid-Schiffs, and Congo red) and immunohistochemical techniques (markers for glial fibrillary acidic protein, ubiquitin, tau, and $\beta$ amyloid). Brain tissue was then examined and the prevalent pathological changes present were described.

\section{STATISTICS}

Regional $\mathrm{CMR}_{\mathrm{glu}}$ values and internal ratios were compared by Student's two sample unpaired $t$ tests between the NPH and control groups. A Bonferroni correction for the effect of multiple comparisons was applied, and an effective $P$ value $<0.0025$ was considered significant. Simple linear regression analysis (Pearson product moment correlation) was performed in the patients with NPH between absolute $\mathrm{rCMR}_{\text {glu }}$ values in cortical and subcortical grey and white matter and the neurological evaluation scores, and also between metabolic impairment scores and resistance to outflow values. The statistical significance limit was set at $\mathbf{P}=0.05$.

\section{Results}

Table 1 presents the clinical, MRI and histological findings for the patients. Gait apraxia was the most frequent symptom (89\%). Eight patients had incontinence, ranging from rare to constant. The mean (SD) MMSE and GDS scores were $22.3(5 \cdot 5)$ and $4 \cdot 4(1 \cdot 2)$, respectively, indicating mild to moderate dementia in the group. Eleven patients (of a total of 14 evaluations) were demented according to the 
Table 1 Clinical, MRI and histopathological data in the group of patients with NPH

\begin{tabular}{|c|c|c|c|c|c|c|c|c|c|}
\hline Case & $\begin{array}{l}\text { Agel } \\
\text { sex }\end{array}$ & Gait & Incontinence & $G D S$ & MMSE & $\begin{array}{l}\text { White } \\
\text { matter lesions }\end{array}$ & $R_{\text {out }}$ & Biopsy & $\begin{array}{l}\text { Clinical } \\
\text { shunt response }\end{array}$ \\
\hline 1 & $63 / M$ & 2 & 2 & 3 & 27 & None & 15 & $\mathrm{AD}$ & No change \\
\hline 2 & $46 / F$ & 1 & 1 & 4 & 13 & None & 25 & No sign path & Worse \\
\hline 3 & $74 / F$ & 3 & 1 & 2 & 27 & Present & 29 & Non-specific & Considerable \\
\hline 4 & $52 / \mathrm{M}$ & 2 & 1 & 6 & 26 & None & 16 & No sign path & No change \\
\hline 5 & $76 / \mathrm{F}$ & 3 & 4 & - & 19 & Present & 29 & Non-specific & Considerable \\
\hline 6 & $60 / M$ & 2 & 1 & 4 & 26 & None & 12 & $\mathrm{AD}$ & Slight \\
\hline 7 & $76 / \mathrm{F}$ & 3 & 3 & 6 & 17 & None & 18 & $\mathrm{AD}$ & Worse \\
\hline 8 & $70 / \mathrm{F}$ & 2 & 2 & 6 & 20 & None & 20 & No sign path & Worse \\
\hline 9 & $68 / M$ & 2 & 2 & 3 & 25 & Present & 29 & CVD & Slight \\
\hline 10 & $70 / \mathrm{F}$ & 2 & 3 & 6 & 27 & None & 20 & $\mathrm{AD}$ & Considerable \\
\hline 11 & $74 / \mathrm{M}$ & 3 & 2 & 4 & 25 & Present & 24 & CVD & Considerable \\
\hline 12 & $57 / M$ & 2 & 1 & 4 & - & Present & 17 & No sign path & No change \\
\hline 13 & $53 / \mathrm{M}$ & 1 & $i$ & 4 & 21 & None & 20 & No sign path & No change \\
\hline 14 & 53/M & 2 & $i$ & 4 & 28 & None & 16 & Non-specific & No change \\
\hline 15 & $49 / \mathrm{F}$ & 2 & 1 & 4 & 29 & Present & 20 & No sign path & No change \\
\hline 16 & $64 / M$ & 2 & 1 & 4 & 23 & Present & 15 & No sign path & No change \\
\hline 17 & $67 / M$ & 4 & 4 & 6 & 12 & Present (CT) & 16 & No sign path & No change \\
\hline 18 & $69 / \mathrm{F}$ & 4 & 1 & 5 & 14 & Present & 16 & No sign path & Not followed \\
\hline
\end{tabular}

Figures in the gait and incontinence columns represent the scores at the clinical evaluation (see Methods for definition); GDS = global deterioration scale ${ }^{24} ; \mathrm{MMSE}=\operatorname{mini}$ mental state examination scores ${ }^{23}$; WM lesions = periventricular/subcortical white matter abnormalities on MRI (on CT in case 17); $R_{\text {our }}=$ resistance to CSF outflow ( $\mathrm{mm} \mathrm{Hg} / \mathrm{ml} / \mathrm{min}$ ) measured by a lumboventricular perfusion test; biopsy = histopathological changes in the right frontal brain tissue; $A D=$ Alzheimer's disease; $C V D=$ cerebrovasperfusion test; biopsy $=$ histopathological changes in the right frontal brain tissue; $\mathrm{AD}=$ Alzheimer's disease; CVD $=$ cerebrovas-
cular disease; No sign path $=$ no significant pathology; Non-specific $=$ non-specific changes; clinical shunt response $=$ clinical evalcular disease; No sign path $=$ no significant pathology; Non-specific $=$ non-specific changes; clinical shunt response $=$ clinical eval-
uation of the response to shunt operation, evaluated three to nine months after shunt operation; no change $=$ no change in uation of the response to shunt operation, evaluated three to nine months after shunt operation; no change = no change in
symptoms (gait, incontinence, and dementia); slight = slight improvement in symptoms; considerable = considerable improvesymptoms (gait, incon
ment in symptoms.

DMS III-R criteria. Eight out of 18 patients with NPH thus showed the complete Hakim's triad. Eight patients showed MRI hyperintensities in the white matter areas, and in one patient white matter lesions were visible on CT (MRI not available). In six patients specific degenerative changes were found in the cerebral parenchyma: cerebrovascular disease in two, typical Alzheimer's disease changes in four. Of the remaining 12 patients, nine did not show any pathological abnormality, while in three patients $(3,5$, and 14$)$ nonspecific degenerative processes were described (subacute encephalomalacia or cortical degeneration).

Nine months after shunt operation, clinical follow up showed that the clinical status was improved in six patients, and in four of these, the improvement was considerable. The group

Table 2 Absolute values and internal asymmetry ratios of regional glucose metabolism measured by PET in patients with normal pressure hydrocephalus and in control subjects

\begin{tabular}{|c|c|c|c|c|}
\hline & \multicolumn{2}{|c|}{ Control $(n=11)$} & \multicolumn{2}{|l|}{$N P H(n=18)$} \\
\hline & $C M R_{\text {glu }}$ & $S A I$ & $C M R_{\text {glu }}$ & $S A I$ \\
\hline Whole cortex & $33 \cdot 4(2 \cdot 6)$ & $-2 \cdot 7(1 \cdot 8)$ & $26.8(3.6)^{\star \star}$ & $-1 \cdot 7(3 \cdot 3) \mathrm{NS}$ \\
\hline Frontal cortex & $32.9(2.5)$ & & $26.4(3.5)^{\star \star \star}$ & $-2.9(5.4)$ Ns \\
\hline Precentral gyrus & $34.0(3 \cdot 7)$ & $-5 \cdot 2(6 \cdot 4)$ & $27.5(3.7)^{\star \star}$ & $-5.3(7 \cdot 6)$ NS \\
\hline Middle gyrus & $31 \cdot 1(2 \cdot 7)$ & $-2 \cdot 0(3 \cdot 2)$ & $25 \cdot 3(3 \cdot 8)^{\star \star}$ & $-1.8(7.0) \mathrm{Ns}$ \\
\hline Middle gyrus & $33.9(2 \cdot 7)$ & $-4.1(3.9)$ & $26 \cdot 6(4 \cdot 3)^{\star \star \star \star}$ & $-4 \cdot 1(8 \cdot 4) \mathrm{NS}$ \\
\hline Inferior gyrus & $33.2(2 \cdot 3)$ & $-3.6(6.4)$ & $26.7(3.7)^{\star \star \star \star}$ & $-2 \cdot 4(6 \cdot 7) \mathrm{Ns}$ \\
\hline \multicolumn{5}{|l|}{$\begin{array}{l}\text { Temporal cortex } \\
\text { Superior gyrus }\end{array}$} \\
\hline $\begin{array}{l}\text { Superior gyrus } \\
\text { and insula }\end{array}$ & $34 \cdot 0(2 \cdot 1)$ & $-4 \cdot 4(2 \cdot 4)$ & $25 \cdot 8(4 \cdot 0)^{\star \star \star}$ & $-2 \cdot 8(4 \cdot 6) \mathrm{NS}$ \\
\hline $\begin{array}{l}\text { and insula } \\
\text { Inferior and }\end{array}$ & & & & \\
\hline \multicolumn{5}{|l|}{$\begin{array}{l}\text { middle gyrus } \\
\text { Parietal cortex }\end{array}$} \\
\hline \multicolumn{5}{|l|}{$\begin{array}{l}\text { Postcentral gyrus } \\
\text { Supramarginal and }\end{array}$} \\
\hline \multirow{2}{*}{\multicolumn{5}{|c|}{$\begin{array}{l}\text { angular gyrus } \\
\text { Occipital cortex }\end{array}$}} \\
\hline & $36 \cdot 1(3 \cdot 3)$ & $-1.6(2.9)$ & $30.7(5.7)^{\star}$ & \\
\hline \multirow{2}{*}{\multicolumn{5}{|c|}{$\begin{array}{l}\text { Central grey matter } \\
\text { Caudate nucleus }\end{array}$}} \\
\hline \multirow{2}{*}{\multicolumn{5}{|c|}{$\begin{array}{l}\text { Caudate nucleus } \\
\text { Lenticular nucleus }\end{array}$}} \\
\hline & & & & \\
\hline \multirow{2}{*}{\multicolumn{5}{|c|}{$\begin{array}{l}\text { Thalamus } \\
\text { White matter }\end{array}$}} \\
\hline & & & & \\
\hline $\begin{array}{l}\text { Anterior/posterior ratios: } \\
\text { Frontal/temporal } \\
\text { Frontal/parietal }\end{array}$ & \multicolumn{2}{|c|}{$\begin{array}{l}0.99(0.04) \\
1.00(0.04)\end{array}$} & \multicolumn{2}{|c|}{$\begin{array}{l}1.02(0.07) \text { Ns } \\
0.99(0.09) \mathrm{Ns}\end{array}$} \\
\hline
\end{tabular}

Values are means (SD). $\mathrm{CMR}_{\mathrm{gl}}=$ regional glucose metabolism $\left(\mu \mathrm{mol} .100 \mathrm{~g}^{-1} \cdot \mathrm{min}^{-1}\right.$; mean of left and right symmetric ROIs); SAL = side to side asymmetry index in (\%), negative values left and right symmetric ROIs); SAL = side to side asymmetry index

${ }_{\star} \mathrm{P}<0.05 ;{ }^{\star \star P} \mathrm{P}<0.001 ;{ }^{\star \star \star} \mathrm{P}<0.0001$ (Student's two sample $t$ test). Values in parenthesis are $\mathrm{P}$ $\star \mathrm{P}<0 \cdot 05 ;{ }^{\star} \mathrm{P}<0.001 ;{ }^{\star \star \star} \mathrm{P}<0.0001$ (Student's two sample $t$ test). Values in parenthesis are $\mathrm{P}$
values before Bonferroni correction for multiple comparisons. NS = non-significant (after Bonferroni correction). of patients that responded to shunt operation included two patients with non-specific changes in their biopsy, two patients with Alzheimer's disease, and two patients with cerebrovascular disease. In eight patients no change was seen after shunt operation, whereas symptoms progressed in three patients.

Table 2 shows absolute $\mathrm{rCMR}_{\mathrm{glu}}$ and the asymmetry indices. The NPH group as a whole showed a pronounced reduction in $\mathrm{rCMR}_{\mathrm{glu}}$ compared with the control group in the entire cortex $(20 \%)$, in the frontal $(20 \%)$, temporal $(22 \%)$, parietal (19\%), and occipital $(15 \%)$ lobes, and in the central grey $(28 \%)$ and white matter $(28 \%)$. The side by side asymmetry indices and anterior/posterior ratios showed no significant differences in any region of interest between the two groups; the coefficient of variation, however, was on average, two to four times higher in the side by side asymmetry index of the regions of interest of the patients with NPH, indicating an inhomogeneous $\mathrm{rCMR}_{\mathrm{glu}}$ reduction.

Figure 1 shows the cortical metabolic patterns of all patients. Whereas $\mathrm{rCMR}_{\text {glu }}$ was globally decreased in the NPH group, this was not the case on an individual level, where focal as well as diffuse significant reductions were observed, and where significantly abnormal side by side asymmetry indices and anterior/ posterior ratios were oddly distributed throughout the cortex. In fact the observed metabolic impairment score values ranged from 0 (cases 3 and 16) to 7 and were determined by abnormal cortical regions localised without a recognisable pattern (fig 1). When, based of the biopsy findings, patients with specific degenerative processes were separated from those with no disease or non-specific changes, no characteristic distribution of the metabolic abnormalities was evident in either of the two subgroups. Both included metabolic patterns ranging from focal reductions in $\mathrm{rCMR}_{\text {glu }}$ or abnormal asymmetry ratios to severe diffuse symmetric or asymmetric decrease in $\mathrm{rCMR}_{\mathrm{glu}}$ (fig 2). Of the two 
Figure 1 Histological findings, PET-FDG patterns and metabolic impairment scores (MIS) in the patients with NPH. $R=$ Right $L=$ left. $X$ represents significantly abnormal (>2.0 SD from control mean values internal asymmetry (side by side asymmetry and/or anterior/posterior ratios), each cross: $M I S=1.0$ represents significantly reduced $(>2 \cdot 0 S D$ from control mean values) absolute $r C M R_{\text {glu }}$ each circle: $M I S=1$.

Combination of both $(\otimes)$ : $M I S=1 \cdot 5$. Biopsy results are shown in parentheses (DAT = dementia of Alzheimer type; $C V D=$ cerebrovascular disease; $N P=$ no pathology; $U C=$ non-specific changes).
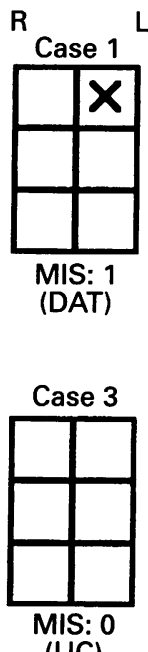

(UC)

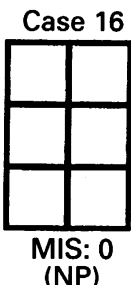

(NP)

Specific neuropathological changes (6 cases)
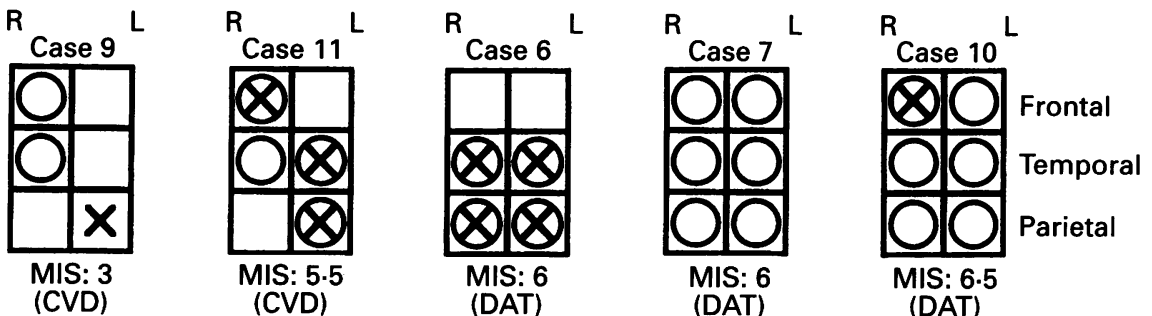

No pathology or non-specific changes (12 cases)
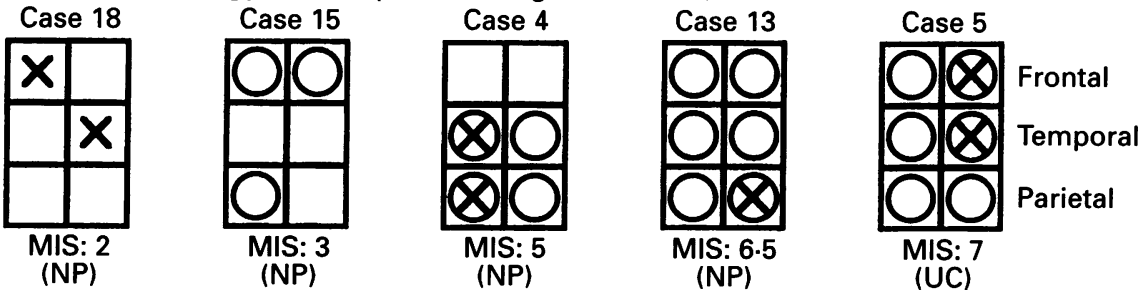

(NP)
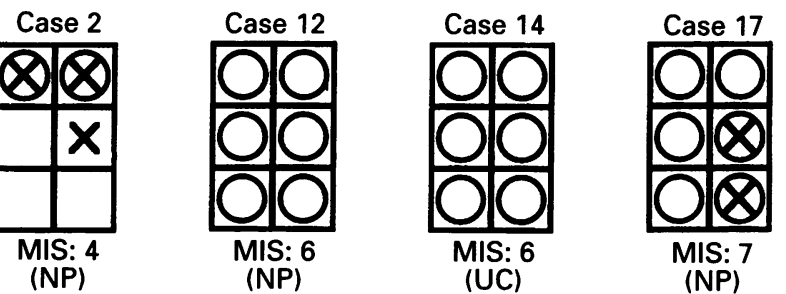

Frontal

Temporal Parietal

(NP)

patients with no abnormal regions (metabolic impairment score $=0$ ), patient 3 showed nonspecific changes and patient 16 no disease at all. The analysis of the metabolic ratios between association cortex and primary cortex or subcortical areas in the patients with NPH showed no significant differences. In particular, the metabolic ratio between association and primary cortex in the four patients with "DAT-NPH" was $0.93(0.04)$ whereas that in

patients with "pure NPH" was $0.97(0.04)(\mathrm{P}>$ $0.05)$; the metabolic ratio between association cortex and central grey matter in the patients with "DAT-NPH" was $0.96(0.07)$ and that in the patients with "pure NPH" was $0.95(0.09)$ $(\mathrm{P}>0.05$ ).

No significant correlation was found between the absolute metabolism in either cortical or white matter regions and the severity of the specific symptoms of NPH (gait apraxia

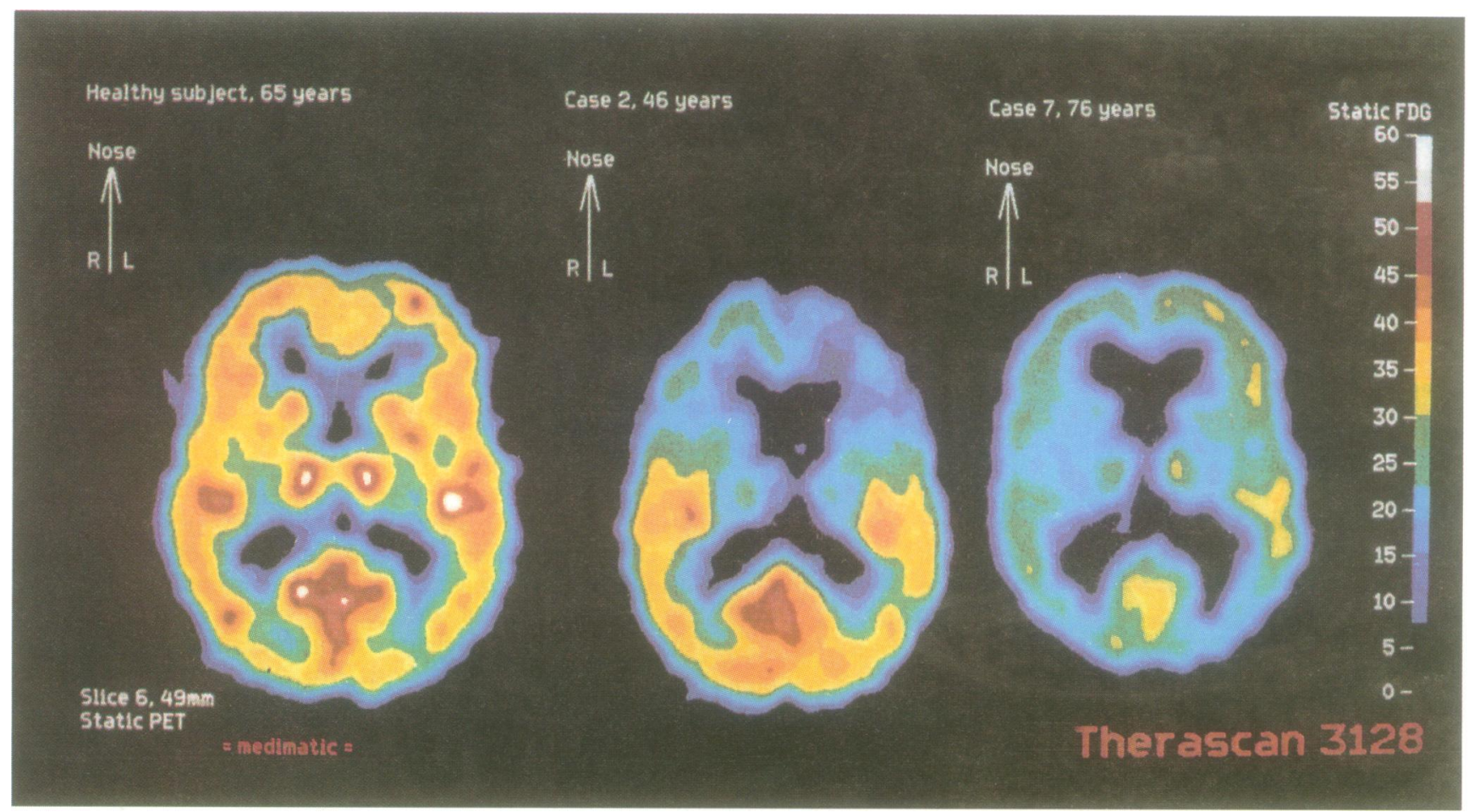

Figure 2 Absolute $r C M R_{\text {glu }}$ images at comparable brain levels of a control subject (left), a patient with NPH with no relevant pathology in the biopsy (case 2, middle), and a patient with NPH with histopathological changes associated with DAT (case 7 , right). A focal (frontal) reduction in glucose metabolism is evident in the middle scan and the scan on the right shows diffuse $C M R_{\text {glu }}$ reduction. 
and urinary incontinence). The severity of dementia, assessed by GDS and MMSE, was significantly correlated with the $\mathrm{rCMR}_{\text {glu }}$ reduction in central grey matter $(P<0.05$ and $P<0.001$, respectively). Likewise, the decrease in frontal cortical metabolism was significantly correlated with MMSE scores $(P<0.005)$. White matter metabolism was not correlated with either of the two dementia evaluation scales. Also, no correlation was found between the metabolic impairment score and the resistance to outflow values, neither when all patients were analysed together, nor when the two groups (nonspecific and specific changes in the biopsies) were analysed separately. When shunt responders were compared with non-responders, no particular metabolic pattern was evident, and accordingly, in both groups MIS values ranged from the lowest $(0)$ to the highest values (7).

\section{Discussion}

The present study, the first PET-FDG report on a prospective group of patients with NPH, showed heterogeneous patterns of cortical metabolic abnormalities, associated with specific degenerative processes (DAT and cerebrovascular disease) in some cases, and to non-specific or no cortical disease in others. The observed metabolic heterogeneity, together with the heterogeneity in the histopathological findings, supports the hypothesis that NPH may be non-specifically related to different degenerative disorders and indicates the necessity of a reassessment of the pathogenic mechanisms of the syndrome.

Previous PET-FDG studies on NPH have reported diffusely reduced preoperative $\mathrm{CMR}_{\mathrm{glu}}{ }^{11}{ }^{1314}$ Jagust et al ${ }^{11}$ measured $\mathrm{rCMR}_{\mathrm{glu}}$ in two patients and stated that PET-FDG could differentiate NPH from DAT-that is, diffuse $\mathrm{rCNR}_{\mathrm{glu}}$ reduction in the first case $v$ predominant temporoparietal changes in the second. By contrast, a patient with global asymmetric reduction and improvement after shunt operation, reported by Kaye et $a l^{13}$ could not be differentiated from patients with DAT on the basis of the PET-FDG pattern. Friedland ${ }^{14}$ described another patient, preoperatively diagnosed as probable Alzheimer's disease, who showed a diffuse hypometabolism, most severe in the parietal cortex, that reversed after shunt surgery, in agreement with clinical and radiological improvement. One PET study of $\mathrm{CMRO}_{2}$ and cerebral blood flow in seven patients with chronic NPH found a reduction of $\mathrm{CMRO}_{2}$ in the cortex, but no regional analysis was performed. ${ }^{12}$ These few PET studies and earlier reports of global reduction in $\mathrm{CMR}_{\mathrm{glu}}$ and $\mathrm{CMRO}_{2}{ }^{30}{ }^{31}$ do not seem to provide sufficient data to define any specific pattern of metabolic derangement in NPH.

Our group of patients with NPH as a whole showed a pronounced diffuse reduction of $\mathrm{CMR}_{\mathrm{glu}}$ when compared with age matched healthy subjects. The PET-FDG individual (metabolic impairment score) analysis correctly identified 16 out of 18 patients as abnor- mal (sensitivity: $89 \%$ ) and nine out of 11 healthy controls as normal (specificity: $82 \%$ ). The distribution of $\mathrm{rCMR}_{\mathrm{glu}}$ deficits within the NPH group was indeed heterogenous, and a characteristic metabolic pattern was not evident. Such heterogeneity, together with that reported in previous SPECT studies, ${ }^{15-18} 20$ suggests the presence of different disorders in patients with "NPH". When grouped according to the histological findings, NPH subgroups still showed a variety of metabolic patterns. In the 12 patients with a metabolic abnormality in their right frontal lobe, it can be reasonably assumed that the metabolic deficit was the expression of the histological change identified in the brain biopsy. In the other cases, undetected degenerative disorders in other areas of the brain may be responsible for the heterogenous metabolic pattern. To exclude this possibility in the subgroup with no specific disease, which could represent the "true idiopathic" NPH patients, we also considered only the eight patients $(2,5,12-15$, 17 , and 18) with a metabolic deficit in the right frontal region: the metabolic heterogeneity was still evident, suggesting that even patients with "biopsy verified true idiopathic" NPH exhibit a heterogeneous PET-FDG pattern. In patients with $\mathrm{DAT}, \mathrm{CMR}_{\mathrm{glu}}$ reductions may asymmetrically involve all neocortical association areas, ${ }^{1032-35}$ and various focal cortical blood flow abnormalities have recently been shown with SPECT-HMPAO. ${ }^{36}$ Likewise, dementia in patients with cerebrovascular disease has consistently been associated with varied focal reductions in cerebral blood flow or $\mathrm{CMR}_{\mathrm{glu}}{ }^{103337}$ In conclusion, in agreement with other reports in the medical literature, heterogenous $\mathrm{rCMR}_{\mathrm{glu}}$ patterns were found in the two subgroups with specific disease but heterogeneity was also present in the patients with NPH with no specific disease in the brain biopsy. This conclusion was also supported by the fact that the metabolic ratios (association cortex/primary cortex and association cortex/central grey matter) did not significantly differ between the four patients with DAT and the 12 with no specific disease in their biopsy - that is, the two subgroups both presented variable PET-FDG patterns. However, a comparison to validate a method for differentiating the two diseases should be made with much larger groups, not consisting of patients who are likely to have both of them.

The presence of different degenerative disorders in the biopsies of our cases may be easily explained by admitting that these patients developed NPH in association with another primary degenerative process. Our patients were referred to Rigshospitalet with a clinicoradiological suspicion of NPH and did not differ in clinical presentation from other NPH groups described in the medical literature. ${ }^{26} 20303138-43$ The diagnosis and the indication for a shunt operation were then confirmed according to well defined hydrodynamic criteria. ${ }^{45}$ The measurement of resistance to outflow $\left(R_{\text {out }}\right)$ as a hydrodynamic variable for CSF disturbances is reproducible and comparable when different infusion and 
perfusion methods are used, ${ }^{2}$ and the normal range is well defined..$^{44} \mathrm{~B}$ wave activity was also registered, but $R_{\text {out }}$ is considered a more valid variable for obstruction of CSF, and is therefore used as the main diagnostic criteria for NPH. Different degenerative disorders, including DAT, progressive supranuclear palsy, and cerebrovascular disease, may themselves lead to a deficit in CSF reabsorption and have been previously described in patients with "NPH". ${ }^{4-51}$ Moreover, the pathophysiology of idiopathic NPH at present is not fully understood and as no unequivocal pathological findings in large groups have been observed, ${ }^{48}$ it is not surprising to find concomitant degenerative processes in some of these patients. In line with this notion, it is interesting that out of six responders to shunt operation, four showed specific degenerative disease in their biopsy (two Alzheimer's disease and two cardiovascular disease). This finding suggests that the symptomatology of these patients may derive from a combination of NPH and a specific degenerative disorder. When shunted, the patients may still improve clinically when NPH contributes significantly to the symptoms. Thus, the finding of a specific degenerative disorder in a brain biopsy from a patient who shows typical symptoms of $\mathrm{NPH}$ (or the finding of coexisting typical symptoms of another degenerative disorder) should not automatically defer the patient from shunting, and in our study shunting seemed to have temporarily halted the inevitable deterioration of two patients with Alzheimer's disease.

From the metabolic patterns it was not possible preoperatively to point out those patients who would benefit from a shunt operation, which again was probably due to the heterogenous nature of NPH, but larger patient groups should be studied to draw any firm conclusions.

The lack of correlation between clinical symptoms typical for NPH and the distribution of cortical metabolic abnormalities suggests that heterogeneous PET-FDG patterns do not reflect the stages of progression of a single disease, but are rather due to the underlying concurrent degenerative disorders. The MMSE scores did correlate with metabolism in the frontal cortex and in central grey matter regions, whereas GDS scores correlated only with central grey matter metabolism. Whatever the underlying pathology may be, this is not surprising since metabolic abnormalities in areas thought to be involved in cognitive functions should lead to a decreased performance in the dementia evaluation tests.

In summary, we found a very heterogeneous pattern of glucose metabolism reduction in a group of consecutive idiopathic patients with NPH diagnosed according to well defined criteria. The presence of different pathological processes supports the hypothesis that NPH may be non-specifically related to multiple degenerative disorders with a common clinical presentation. The present study also showed that different parenchymal degenerations, associated with the development of NPH syn- drome, were characterised by heterogeneous PET-FDG patterns, and that even patients with no specific histopathological changes, which may represent the patients with "true idiopathic" NPH, did not present a typical pattern of metabolic impairment. Although a clear explanation for the pathogenic mechanisms of NPH and the degenerative processes leading to dementia is not achievable yet, we think that the integration of morphofunctional brain imaging modalities is required for a better understanding of these diseases.

The excellent technical assistance of Karin Stahr, Pia Tejmer, and Gerda Thomsen is gratefully acknowledged. This study was supported by grants from the Danish Medical Research Council; the Lundbeck Foundation; the Danish Research Founcil, the Lundbeck Foundation; the Danish Hospital Foundation for Medical Research; Region of Copenhagen, the Fkovgaard's Foundation; and the Foundation of 17-12-1981.

1 Hakim S, Adams RD. The special clinical problem of symptomatic hydrocephalus with normal cerebrospinal fluid pressure. Observations on cerebrospinal fluid fluid pressure. Observations on cerebro
hydrodynamics. $\mathcal{F}$ Neurol Sci 1965;2:307-27.

2 Gjerris F, Børgesen SE. Current concepts of measurement of cerebrospinal fluid absorption and biomechanics of hydrocephalus. Adv Tech Stand Neurosurg 1992;19: 145-77.

3 Black PM. The normal pressure hydrocephalus syndrome. In: Scott RM, ed. Hydrocephalus (concepts of neurosurgery, III). Baltimore: Williams and Wilkins, 1990:109-14.

4 Børgesen SE, Gjerris F, Sørensen SC. Intracranial pressure and conductance to outflow of CSF in normal pressure hydrocephalus. F Neurosurg 1979;50:489-93.

5 Børgesen SE, Gjerris F. The predictive value of conductance to outflow of CSF in normal pressure hydrocephalus. Brain 1982;105:65-86.

6 Vanneste J, Augustijn P, Dirven C, Tan WF, Goedhart $Z D$. Shunting normal pressure hydrocephalus: do the benefits outweigh the risks? A multicenter study and benefits outweigh the risks? A multicen
literature review. Neurology 1992;42:54-9.

7 Frackowiack RSJ, Pozzilli C, Legg NJ, et al. Regional cerebral oxygen supply and utilization in dementia. A clinical and physiological study with oxygen-15 and positron tomography. Brain 1981;104:753-78.

8 Hoffman JM, Guze BH, Baxter LR, et al. ${ }^{18} \mathrm{~F}$-Fluorodeoxyglucose (FDG) and positron emission tomography (PET) in aging and dementia. A decade of studies. Eur Neurol 1989;29(suppl 3):16-24.

9 Rapoport SI. Positron emission tomography in Alzheimer's disease in relation to disease pathogenesis: a critical review. Cerebrovasc Brain Metab Rev 1991;3:297-335.

10 Mazziotta JC, Frackowiack RSJ, Phelps ME. The use of positron emission tomography in the clinical assessment positron emission tomography in the clinical as

11 Jagust WJ, Friedland RP, Budinger TF. Positron emission tomography with $\left({ }^{18} \mathrm{~F}\right)$ fluorodeoxyglucose differentiates normal pressure hydrocephalus from Alzheimer-type normal pressure hydrocephalus from Alzheimer-type
dementia $\Im$ Neurol Neurosurg Psychiatry 1985;48:1091-6.

12 Brooks DJ, Beaney RP, Powell M, et al. Studies on cerebral oxygen metabolism, blood flow, and blood volume, in patients with hydrocephalus before and after surgical decompression, using positron emission tomography. Brain 1986;109:613-28.

13 Kaye JA, Grady CL, Haxby JV, et al. Plasticity in the aging brain. Reversibility of anatomic, metabolic, and cognitive deficits in normal pressure hydrocephalus following shunt surgery. Arch Neurol 1990;47:1336-41.

14 Friedland RP. "Normal"-pressure hydrocephalus and the saga of the treatable dementias. $f A M A$ 1989;262: 2577-81.

15 Vorstrup S, Christensen J, Gjerris F, et al. Cerebral blood flow in patients with normal-pressure hydrocephalus before and after shunting. $\mathcal{F}$ Neurosurg 1987;66:379-87.

16 Graff-Radford NR, Rezai K, Godersky JC, et al. Regional cerebral blood flow in normal pressure hydrocephalus. $\mathcal{f}$ Neurol Neurosurg Psychiatry 1987;50:1589-96.

17 Moretti JL, Sergent A, Louarn F, et al. Cortical perfusion assessment with 123I-isopropyl amphetamine (123IIAMP) in normal pressure hydrocephalus (NPH). Eur $\mathcal{f}$ Nucl Med 1988;14:13-9.

18 Granado JM, Daz F, Alday R. Evaluation of brain SPECT in the diagnosis and prognosis of the normal pressure hydrocephalus syndrome. Acta Neurochir 1991;112: 88-91.

19 Kimura M, Tanaka A, Yoshinaga S. Significance of periventricular hemodynamics in normal pressure hydrocephalus. Neurosurgery 1992;30:701-4.

20 Waldemar G, Schmidt JF, Delecluse F, et al. High resolution SPECT with ${ }^{99 \mathrm{~m} T c]}-d, l$-HMPAO in normal pressure hydrocephalus before and after shunt operation. 7 Neurol Neurosurg Psychiatry 1993;52:655-64.

21 Evans WA. An encephalographic ratio for estimating ventricular enlargement and cerebral atrophy. Arch Neurol 1942;47:931-7.

22 DSM III-R. Diagnostic and statistical manual of mental disor- 
ders. 3rd (revised) ed, Washington: American Psychiatric Association 1987.

23 Folstein MF, Folstein SE. McHugh PR. Mini-mental state: a practical method for grading the cognitive state of a practical method for grading the cognitive state of
patients for the clinician. $\mathcal{F}$ Psychiat Res $1975 ; 12: 189-98$.

patients for the clinician. F Psychiat Res 1975;12:189-98.
24 Reisberg B, Ferris SH, de Leon M, et al. The global deterioration scale for assessment of primary degenerative dementia. Am f Psychiatry 1982;139:1136-9.

25 Cooke BE, Evans AC, Fanthome EO, et al. Performance figures and images from the Therascan 3128 positron emission tomography. IEEE Trans Nucl Sci 1984;NS31 640-4.

26 Sokoloff L, Reivich M, Kennedy C, et al. The C-14 deoxyglucose method for the measurement of local cerebral glucose utilization: theory, procedure, and normal values in the conscious and anesthetized albino rat. $\mathcal{f}$ Neurochem 1977;28:897-916.

27 Brooks RA. Alternative formula for glucose utilisation using labelled deoxyglucose. $f$ Nucl Med 1982;23: using

28 Aquilonius SM, Eckernäs SÅ. A colour atlas of the human brain. Adapted to computed tomography. Stockholm: Esselte Studium, 1980.

29 Waldemar G, Hasselbalch S, Andersen AR, et al. ${ }^{99 \mathrm{~m} T c-d, l}$ HMPAO and SPECT of the brain in normal aging. f Cereb Blood Flow Metab 1991;11:508-21.

30 Grubb RL, Raichle ME, Gado MH, et al. Cerebral blood flow, oxygen utilization and blood volume in dementia. Neurology 1977;27:905-10

31 Lying-Tunnell U, Lindblad BS, Malmund HO, Persson B. Cerebral blood flow and metabolic rate of oxygen, glucose, lactate, pyruvate, ketone bodies and amino acids. Acta Neurol Scand 1981;63:337-50.

32 Benson FD, PET/Dementia: an update. Neurobiol 1988;9: 87-8.

33 Duara $\mathrm{R}$, Barker $\mathrm{W}$, Loewenstein $\mathrm{D}$, et al. Sensitivity and specificity of positron emission tomography and magnetic resonance imaging studies in Alzheimer's disease and multi-infarct dementia. Eur Neurol 1989;29(suppl 3): 9-15

34 Meyer $\mathrm{E}$. The use of positron emission tomography in the early diagnosis of senile dementia. In: Bergner $\mathbf{M}$ Reisberg B, eds. Diagnosis and treatment of senile dementia. Berlin: Springer-Verlag, 1989;243-58.

35 Powers WJ, Perlmutter JS, Videen TO, et al. Blinded clinical evaluation of positron emission tomography for diagnosis of probable Alzheimer's disease. Neurolog 1992;42:765-70.

36 Waldemar G, Bruhn P, Kristensen M, Johnsen A Paulson OB, Lassen NA. Heterogeneity of neocortical blood flow deficits in dementia of the Alzheimer type: a [99mTc]-d,l-HMPAO SPECT study. F Neurol Neurosurg Psychiatry 1994;57:285-95,

37 Benson DF, Kuhl DE, Hawkins $R$, et al. The fluorodeoxyglucose ${ }^{18} \mathrm{~F}$ scan in Alzheimer's disease and multideoxyglucose ${ }^{18} \mathrm{~F}$ scan in Alzheimer's disease
infarct dementia. Arch Neurol 1983;40:711-4.

38 Greenberg JO, Shenkin HA, Adam R. Idiopathic normal pressure hydrocephalus-a report of 73 patients. $f$ Neurol Neurosurg Psychiarry 1973;40:336-41.

39 Jacobs L, Conti D, Kinkel WR, Manning EJ. "Normalpressure" hydrocephalus. Relationship of clinical and radiographic findings to improvement following shunt surgery. $\mathcal{F A M A}$ 1976;235:510-2.

40 Fisher CM. The clinical picture in occult hydrocephalus. Clin Neurosurg 1977;24:270-84.

41 Fisher CM. Hydrocephalus as a cause of disturbances of gait in the elderly. Neurology 1982;32:1358-63.

42 Meyer JS, Tachibana H, Hardenberg JP, et al. Normal pressure hydrocephalus. Influences on cerebral hemodynamic and cerebrospinal fluid pressure-chemical autoregnamic and cerebrospinal fuid pressure-ch

43 Larsson A, Wikkelso C, Bilting M, Stephensen H. Clinical parameters in 74 consecutive patients shunt operated for
normal pressure hydrocephalus. Acta Neurol Scand normal pressure

44 Albech M, Gjerris F, Børgesen SE, et al. The resistance to cerebrospinal fluid outflow in healthy volunteers. $\mathcal{F}$ Neurosurg 1991;74:597-600.

45 Coblentz JM, Mattis S, Zingesser LH, et al. Presenile dementia. Clinical aspects and evaluation of cerbrospinal fluid hydrodynamics. Arch Neurol 1973;29:299-308.

46 Sohn RS, Siegel BA. Gado M, Torack RM. Alzheimer's disease with abnormal cerebrospinal fluid flow. Neurology 1973;23:1058-65.

47 Earnest MP, Fahn S, Karp JH, Rowland LP. Normal pressure hydrocephalus and hypertensive cerebrovascular pressure hydrocephalus and hyperten
disease. Arch Neurol 1974;31:262-6.

48 Jellinger $\mathrm{K}$. Neuropathological aspects of dementias resulting from abnormal blood and cerebrospinal fluid dynamics. from abnormal blood and cerebro
Acta Neurol Belg 1976;76:83-102.

49 Morariu MA. Progressive supranuclear palsy and normal pressure hydrocephalus. Neurology 197929:1544-6.

50 Bradley WG, Whittemore AR. Watanabe AS, et al. Association of deep white matter infarction with chronic communicating hydrocephalus. Implications regarding the possible origin of normal pressure hydrocephalus. $A m$ f Neuro Radiol 1991;12:31-9.

51 Kirkpatrick JB, Hayman LA. White matter lesion in MR imaging of clinically healthy brains of elderly subjects: possible pathologic basis. Radiology 1987;162:509-11. 